\title{
ENVEJECIMIENTO Y MIGRACION EN UNA COMUNIDAD ANDINA: LIVITACA EN 1689 *
}

\author{
CLARA LOPEZ BELTRAN \\ Columbia University
}

Recientes estudios sobre la población indígena en América han puesto de relieve la abrupta disminución demográfica ocurrida en los dos siglos que sucedieron a la conquista española. Una mayor mortalidad y una menor fecundidad alteraron también la estructura de la población, aumentando en particular su envejecimiento. Por otra parte, las corrientes migratorias fueron cuantiosas y se han revelado de fundamental importancia para la comprensión del desarrollo socioeconómico de la zona ${ }^{1}$. Dentro de este conjunto de proposiciones, el presente estudio quiere examinar lo sucedido en una región típica de campesinos quechuas en las tierras altas del sur peruano; región de comunidades tradicionales y de presencia española en las haciendas. Dos son los puntos en los que me detendré en particular: el avanzado envejecimiento del grupo, según se desprende de su distribución por edades, y la magnitud y dirección de las migraciones. Si los «historiadores y antropólogos han solido concebir los pueblos de indios como asentamientos estables en zonas rurales» ${ }^{2}$, los nuevos análisis muestran, por el contrario, que la población indígena del espacio peruano experimentó fuertes migraciones intra $e$ interregionales, empujadas en particular por la necesidad de evadir las imposiciones estatales coloniales.

Mi análisis se basa en el padrón general de indios de 1689 de la doctrina de San Sebastián de Livitaca, con su anexo el pueblo de Totora, en la provincia de Chumbivilcas, cerca del Cuzco, que don Manuel de Mollinedo envió en respuesta a los insistentes pedidos de la Corona, a cada parroquia de su diócesis, requiriendo un informe-relación de su situación y condiciones. El obispo recibió 135 informes diversos en su forma; desde cuidadosas descripciones - por ejemplo, el de la doctrina de Capacmarca en la provincia de

\footnotetext{
* Al profesor Nicolás Sánchez-Albornoz - maestro incomparable-, mi vivo agradecimiento por su generosa y paciente ayuda, sin la cual este estudio difícilmente habría podido ser concluido. Mi homenaje a su labor.

' Véanse Sánchez-Albornoz (1982), (1982 a) y (1983); Saignes (1978), (1979) y (1981).

2 Sánchez-Albornoz (1983), p. 13.
} 
Chumbivilca- hasta apresuradas síntesis de compromiso, y entre ellos tres padrones. Estas relaciones se conservan en un legajo en el Archivo General de Indias, pero he usado para el presente estudio la versión publicada recientemente ${ }^{3}$.

La estructura demográfica de Livitaca sigue, en cierto modo, las líneas generales de la sociedad comunitaria andina de fines del siglo XvII, a la manera puesta de manifiesto por Morner: «anormal aun para su época y medio geográfico $\mathrm{y}$, en todo caso, difícilmente aplicable fuera de una zona bien delimitada» ${ }^{4}$.

El padrón de Livitaca fue confeccionado para la ocasión por el párroco local, el cura mercedario fray Gonzalo Peralta de Vacca, asistido -según su declaración - por sus ayudantes religiosos, el gobernador (indigena, por supuesto) y los curacas o caciques de los diferentes ayllus ${ }^{5}$.

$\mathrm{El}$ área a la que se refiere el censo es una circunscripción religiosa (doctrina) que responde a las características de las antiguas comunidades, territorialmente esparcidas en más de un nivel ecológico. Incluye también fincas agrícolas de españoles (estancias) surgidas después de la conquista y que daban refugio a indios forasteros y comuneros fugitivos. Lamentablemente no se tienen datos sobre las dimensiones de los terrenos que posee la comunidad, ni tampoco de aquéllos ocupados para la vivienda, cultivo y ganadería, así como la distancia entre ellos; datos que ayudarían a la comprensión de la relación hombre-espacio, hombre-territorio.

\section{SITUACION GEOGRAFICA}

La doctrina de Livitaca se encuentra al S-SE de la ciudad del Cuzco, en la provincia de Chumbivilcas del actual Departamento del Cuzco ${ }^{6}$. Según una relación geográfica, dista de dicha ciudad unas 16 leguas, o $96 \mathrm{Km}$. según el Atlas? ${ }^{?}$. El pueblo principal (Livitaca) se sitúa a una altura de 3.741 m. s. n. m., en la ladera de los altos cerros, a media legua de un río caudaloso, el Quicha, y tiene un clima muy frío. Al igual que en nuestra época, prevalecía la ganadería, lo que dio pie a una notable actividad textil ${ }^{8}$.

${ }^{3}$ Villanueva Urteaga (1982).

- Mörner (1978), p. 10.

s Villanueva Urteaga (1982), p. 320.

- Cook (1981).

7 El distrito del Cuzco consta de 13 provincias y 101 distritos. Una de las provincias es Chumbivilcas, con capital Santo Tomás, y sus distritos son Santo Tomás, Capacmarca, Qolquemarca, Chamaca, Livitaca, Llusa, Quinota y Velille. Véase Atlas (1970), p. 432. Véase, también, Jiménez de la Espada (1965), p. 323.

- Jiménez de la Espada (1965), p. 325. 
En 1786 se encontraban allí instalados dos obrajes ${ }^{9}$. Su producción agrícola se centraba en la patata o papa y en la quinua (chenopodium quinoa); en cambio, hubo poca producción de granos ${ }^{10}$. El pueblo anexo de Totora -así llamado por la abundancia de este tipo de cañas en sus alrededores- se sitúa en un amplio valle descrito como una hoyada a tres leguas del pueblo principal —dos y media dice el padrón en estudio-, más o menos unos $18 \mathrm{Km}$; tiene clima templado y la producción principal era el maíz".

Siguiendo el esquema de Dollfus para los geosistemas por pisos térmicos, se puede decir que Livitaca corresponde al geosistema frío y Totora al geosistema templado. El primero tiene una temperatura media anual inferior a los $10^{\circ} \mathrm{C}$, las heladas son frecuentes especialmente de noche, fenómeno que se aprovecha en modo práctico para el proceso de deshidratación de la patata (confección de chuño). Se ubica a alturas superiores a 3.400 metros, y tanto animales como plantas se han ido adaptando' a estas condiciones del medio limitadas por la disminución de la presión atmosférica. El límite de poblamiento es el de la posible utilización del medio para la agricultura, ganadería o actividades mineras, sin que la altura haya representado un obstáculo para los habitantes nativos. El segundo geosistema es mucho más benigno, su temperatura media anual fluctúa entre los 11 y $17^{\circ} \mathrm{C}$ y ha sido transformado por el hombre utilizando terrazas de cultivo alli donde la humedad no es constante ${ }^{12}$.

La posición geográfica y las. características climáticas adscriben a la comunidad que me ocupa dentro del modelo propuesto por Murra en su teoría del archipiélago de pisos ecológicos. Según ésta, la estrategia espacial de estos grupos étnicos consistía en obtener la mayor autonomía económica mediante el dominio de tierras situadas en diferentes pisos ecológicos. El sistema se basaba en la complementariedad y redistribución de la producción regidos por el principio de reciprocidad. Este intercambio no se limita únicamente a los campos de circulación y consumo de bienes, sino que también abarca el proceso de producción, tanto en los medios de producción (la tierra o animales de trabajo y otros) como en la fuerza de trabajo (ayuda mutua en las labores agrícolas y/o servicios) ${ }^{13}$.

- Mörner (1978), p. 104, cuadro LVII.

10 Jiménez de la Espada (1965), p. 325.

1 Jiménez de la Espada (1965), p. 324, y Mörner (1978), p. 72.

12 Dollfus (1981), pp. 20-26.

${ }^{13}$ Murra (1975). 


\section{LOS POBLADORES}

No se tienen noticias sobre el número de habitantes que concentraba $\mathrm{Li}$ vitaca en tiempos prehispánicos. Sabemos, sin embargo, que formaban parte de la etnia de los Chumbivilvas, dominados por los incas, transformándose con la organización colonial en la provincia del mismo nombre ${ }^{14}$.

Dentro de la provincia de Chumbivilcas, la doctrina de Livitaca mantiene constante su importancia y peso poblacional, esto es, alrededor del 11 por 100 del total poblacional. Ni crece ni se reduce, sino que sigue el ritmo medio de desenvolvimiento del área. Seguir entonces el desarrollo poblacional de esta provincia sirve de marco de referencia al de la doctrina.

Demográficamente, la primera información sobre la provincia es tardía, data de la Visita General de Toledo en 1572. Allí la población provincial ascendía a 30.304 habitantes (véase cuadro 1), y en un lapso de treinta años perdió unos 7.000 pobladores, lo que representa un 24 por 100 menos de la cifra inicial, o sea, un decrecimiento del $-0,88$ anual. En ciento treinta y nueve años (1615-1754), la población siguió disminuyendo a un ritmo anual de $-0,69$ por 100 , y a partir de entonces, mediados del siglo xvill, parece que se inicia una recuperación. La población, que había quedado reducida a 8.145 habitantes, experimentó un incremento de 3.330 personas en treinta y ocho años, a razón de 0,89 por 100 al año, y de 0,43 por 100 entre 1786 y 1812. El mayor aumento fue entonces del elemtnto no indígena. Cuando el obispo Mollinedo recorre su diócesis en 1674 encuentra que muchas veces la única persona blanca que vivía en las doctrinas esparcidas entre las montañas era el doctrinero. Este se veía obligado a vivir igual que sus filigreses, en austeridad y en constante lucha contra el medio ambiente ${ }^{15}$. Los mestizos - decía - son los enemigos capitales de los indios, pero que en 1786 llegaron a representar el 17 por 100 de la población provincial establecidos en las estancias $\mathrm{y}$ haciendas agrícolas ${ }^{16}$.

La doctrina de Livitaca, al igual que toda la provincia, sufre una fase de decrecimiento poblacional que se inicia en el siglo xvi y se extiende a lo largo del siglo xvir, para recuperarse después de 1750. En el primer registro de

${ }^{14}$ Cuando los chumbivilcas cayeron bajo el dominio imperial de los incas, en tiempos prehispánicos, perdieron el propio idioma en favor del quechua. Vestían una camiseta hasta las rodillas sin mangas (uncu) y, en la cabeza, sus característicos gorros (llautos, chullus o lluchus) de color blanco y negro, divisa que representaba su filiación étnica; bajo el incario estuvo prohibido por ley que se cambiara, y perduró luego durante la colonia. Sus casas eran de adobe y piedra, «la forma de sus edificios... como el de las ciudades*, pero con techo de paja, y sólo debían adquirir la madera de otras regiones. En la guerra peleaban con hondas y mazas de cobre, y fueron llevados por los incas a combatir contra Quito y los cañares. Jiménez de la Espada (1965), pp. 310 y 325.

${ }^{13}$ Colin (1966), p. 27.

16 Archivo General de Indias, Lima, 306; documento citado por Colin. 

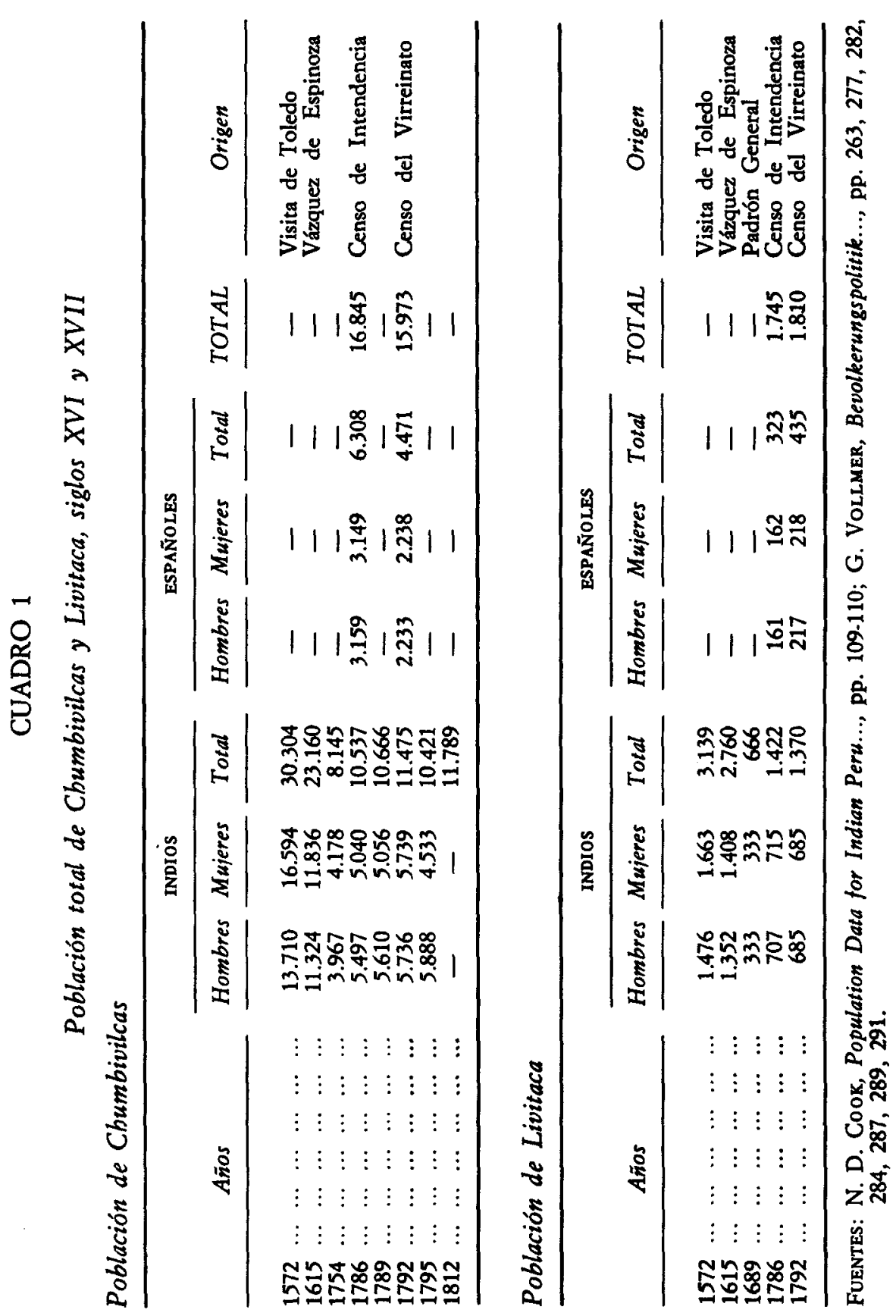
1572 se señalan 3.139 habitantes, con 609 tributarios (véase cuadro 1) ${ }^{17}$; Vázquez de Espinoza indica 2.760 habitantes, con 479 tributarios ${ }^{18}$, y el padrón general de 1689 señala 666 residentes indígenas junto a un número no anotado de no indígenas ${ }^{19}$. Así, en el último cuarto del siglo xvi pierde el 12 por 100 de sus habitantes, a razón de $-0,51$ por 100 anual; y desde 1602 a 1689 su decrecimiento es del orden del $-1,4$ por 100 al año. Un siglo después (1786) se cuentan 1.750 habitantes ( 1.420 indios y 320 españoles), y seis años más tarde (1792) hay ya 1.800 (1.370 indios y 430 españoles). El sector no indígena aumenta en un tercio camino de la españolización, o más bien mestización de la población. El número de estancias aumenta de 6 a 19 durante el siglo xvIII, albergando de preferencia habitantes no indígenas. El ayllu Chagnama es ejemplo extremo; su población comunitaria disminuye y se quintuplica el número de estancias (de 2 a 10 ) ${ }^{20}$.

Para un análisis de la composición poblacional por sexo, edad y vínculo familiar, hay que considerar de antemano las limitaciones de la fuente analizada. Estas responden, más que a defectos en sí, a características comunes de este tipo de documentos de la administración colonial. Su origen fiscal refleja especial interés por empadronar al sector real o potencialmente tributario. Hay que señalar, además, que la noción de hombre andino se calculaba como punto de referencia social -en lugar de tener 5 ó 25 años, se era «niño» o «adulto», lo que da un cálculo cronológico aproximado- ${ }^{21}$.

El conjunto de habitantes de la doctrina de Livitaca en 1689 está distribuido por igual entre hombres y mujeres: 333 personas de cada grupo, con una relación de masculinidad de 100 . Este promedio, sin embargo, se distorsiona en las fases intermedias de edad, donde las mujeres superan el número de hombres entre los 20 y 40 años. Hay muchos hombres viejos y pocas niñas menores de nueve años. Los modelos demográficos aceptan como normal el nacimiento de una mayor cantidad de varones y también una más alta mortalidad infantil masculina. La diferencia señalada es, sin embargo, notable y sugiere una omisión de niñas en el registro de tributarios, fenómeno que se da en otros lugares y momentos ${ }^{22}$.

Nuestra fuente anota una población activa del 46 por 100 del total. Esta es considerada la real fuerza productiva, y son las personas entre 15 y 49 años. Los hombres - potencia productiva por excelencia- son el 20 por $100 \mathrm{del}$

${ }^{17}$ Son 1.476 hombres y 1.663 mujeres. Cook (1975), p. 153.

u Son 1.352 hombres y 1.408 mujeres. Cook (1982), p. 109.

19 Vollmer (1967).

${ }^{20}$ Mörner (1978), p. 104

${ }^{21}$ Renique y Trelles (1977), p. 171, y López Beltrán (1985), pp. 7 y 15.

22 \&... en cuanto a las niñas, hay razones para sostener que hubo un subregistro...». Sánchez-Albornoz (1983), p. 20. 


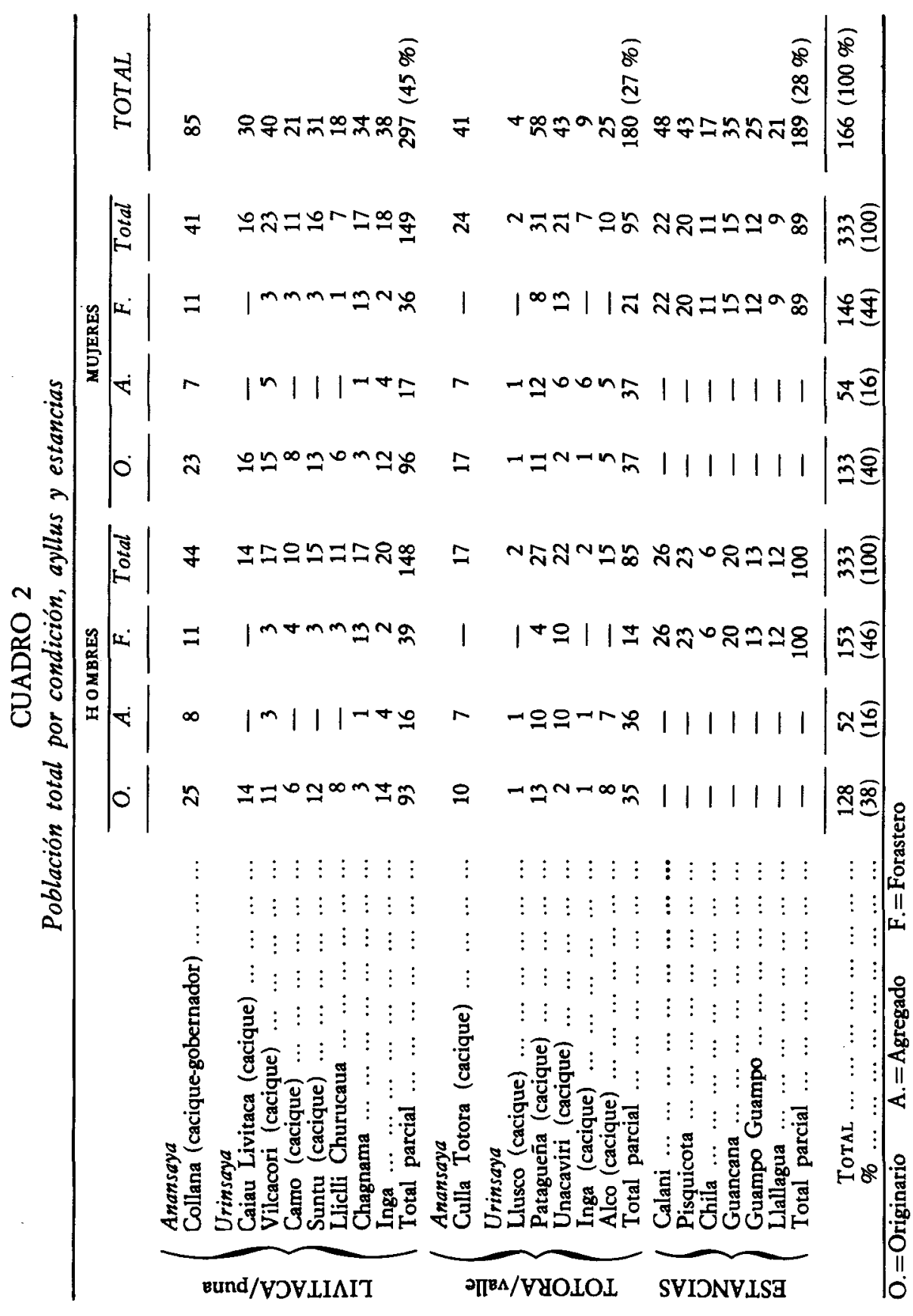


total y el 41 por 100 del sector masculino en general ( 137 personas), y de ellos dependería el mantenimiento y reproducción de la comunidad y el pago de las imposiciones estatales. Sin embargo, las personas formalmente gravadas con la tasa anual o tributarios son los varones originarios de 18 a 50 años (caciques, impedidos, cantores llamados exentos). En Livitaca también los agregados, o sea, los forasteros asimilados en edad de tributar, pagan mitad de la tasa anual.

Llama la atención el alto número de habitantes de más de 50 años (un tercio de la población), y muchos de ellos de edad avanzada. Es especialmente notorio el gran número de viejos de más de 60 años. ¿Cómo explicar esta concentración de viejos? La emigración de población activa joven parece ser causa importante. Aquí, como en otras áreas, la evasión de las pesadas cargas tributarias impulsa a los comunarios a emigrar hacia otras comunidades o haciendas con el fin de hacerse pasar por forasteros y así evadir el pago de las pesadas contribuciones fiscales. De este modo, el número de originarios en edad de tributar es menor, y especialmente reducido en la categoría de 20 a 29 años en que los forasteros son ampliamente el doble. Los viejos originarios son el grupo más consistente -43 varones y 43 mujeres-, junto a un número similar de pares forasteros (véase gráfico 1 ).

Este fenómeno podría también responder parcialmente a un probable retorno de los migrantes al lugar de origen, quienes superado el límite de edad tributaria quieran integrarse nuevamente a su propio ayllu, adquiriendo tal vez sus antiguos derechos de originarios. Tal sugerencia queda pendiente de confirmación con el análisis de otras y diferentes fuentes. El abandono definitivo o temporal de mano de obra deja al grupo debilitado en su potencial productivo, agravándose con el retorno de los viejos — si así fuera - por el aumento del número de miembros en condiciones de dependencia.

\section{FAMILIA Y REPRODUCCION}

La familia nuclear consta de muy pocos miembros, en muchos casos sólo los cónyuges. Para medir el tamaño de la familia se han dejado al margen del recuento a viudos y solteros de uno y otro sexo. Las unidades familiares serán, así, grupos compuestos por padre, madre e hijos si los hay. De éstos, más de la mitad ( 52 por 100) no registran hijos (véase cuadro 5 ), mientras que en Sipesipe (Cochabamba) son el 26 por 100 en 1645, y en Yaque-Collaguas (Arequipa) el 32 por 100 en $1591^{23}$. De las 106 familias con hijos, 65 tie-

23 Sánchez-Albornoz (1983) y Renique y Trelles (1977), p. 182. 


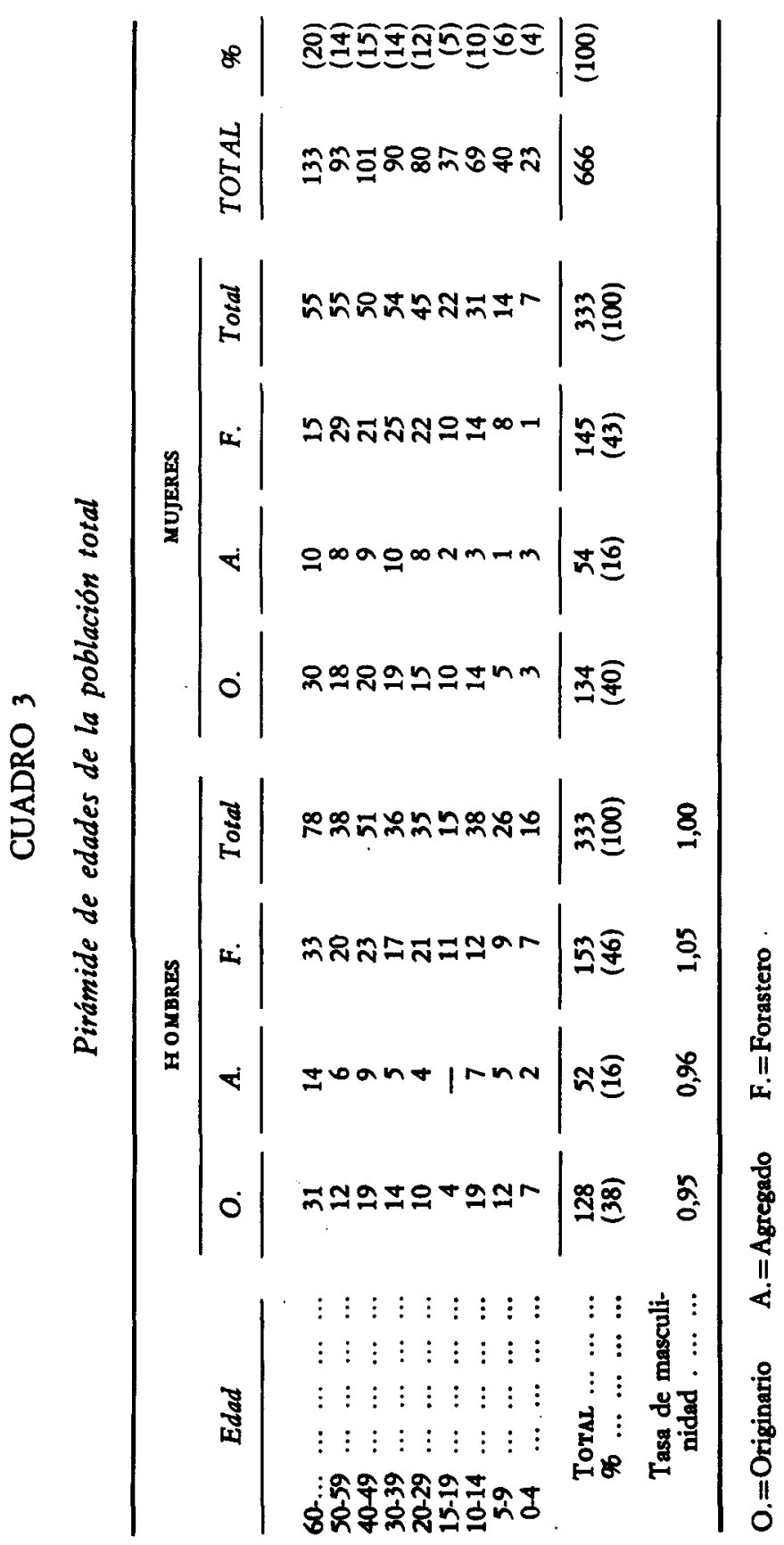




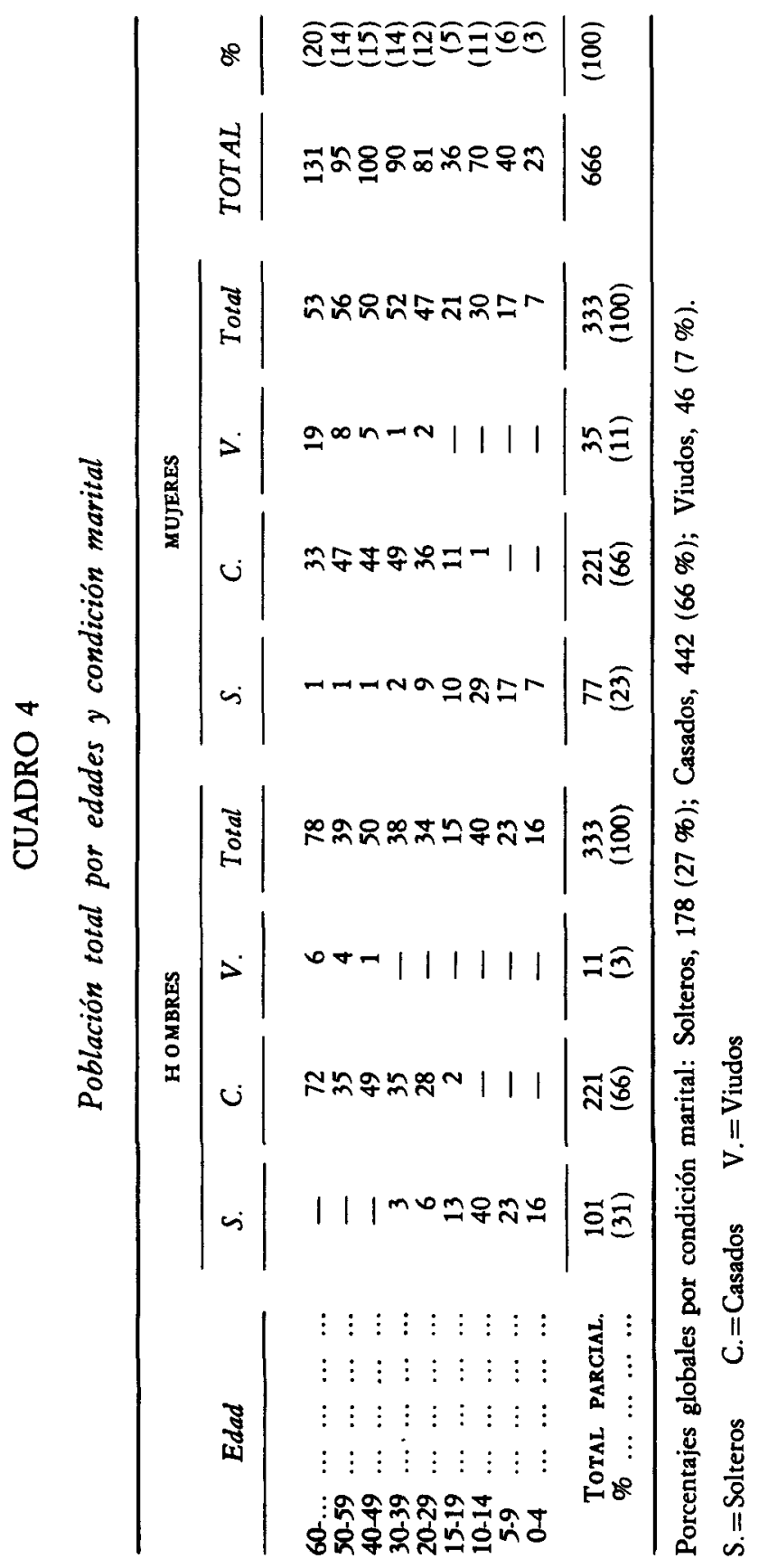




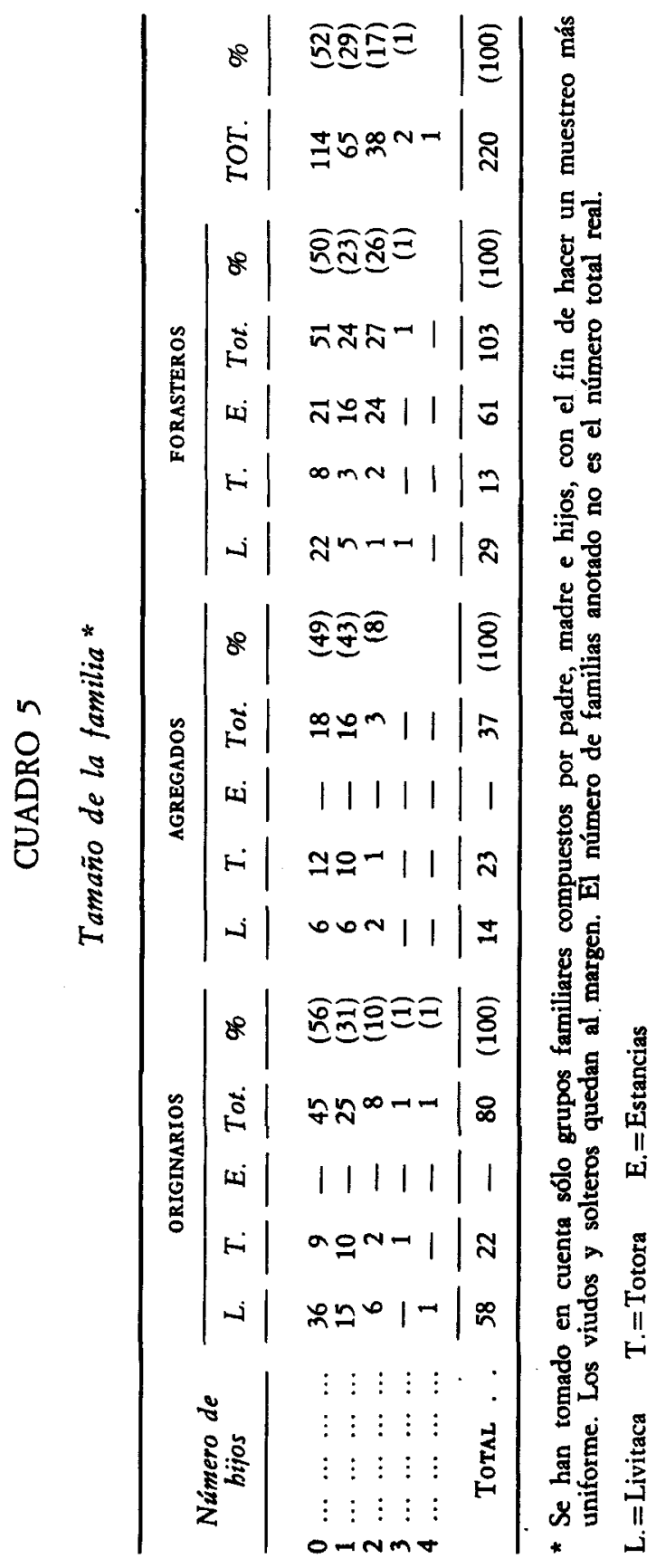


nen 1 sólo ( 61 por 100), 38 familias tienen 2 ( 35 por 100) y, en modo excepcional, 2 familias tienen 3 hijos. El único caso de 4 hijos se da en la familia de curacas. Hay 1,32 hijos por familia con hijos, o 0,69 si se incluyen a las parejas sin hijos. Considerando que tendencialmente son un grupo de edad avanzada, es de pensar que gran parte de los hijos han formado ya su propio núcleo familiar dejando la casa paterna.

Entre los originarios más de la mitad de las parejas no tienen hijos, y un tercio tiene 1 y tan sólo el 10 por 100 tienen 2. Entre los agregados la mayor parte de los matrimonios tiene 1 hijo y 2 los forasteros establecidos en las estancias, coincidiendo así con la tendencia de la región cuzqueña, donde el tamaño promedio de la familia y la relación niño-adulto es más alta entre los forasteros que entre los originarios ${ }^{24}$. Entonces, las jọvenes parejas de originarios estarían ausentes, y aquellas que se atreven a sostener familias más grandes están en las estancias, tal vez porque se sienten protegidos por el dueño español o mestizo.

La población femenina está compuesta por un 40 por 100 de originarios, 16 por 100 de agregados y 43 por 100 de forasteros (véase cuadro 3$)^{25}$. El 51 por 100 de ellas es población activa con mayoría forastera ( 78 de 171 personas) y son también mano de obra efectiva en relación a la producción. Hay que considerar que el trabajo femenino contempla, además del papel tradicional dentro de la estructura familiar —el cuidado diario de la casa y de los hijos-, la participación en el trabajo agrícola, en la siembra y en la cosecha, así como en la manufactura textil. Ambas actividades ayudan al pago del tributo, ya sea en especie como en los primeros tiempos (productos agrícolas y tejidos de cumbi y abasca), ya en trabajo para producir excedentes con los cuales obtener beneficio en moneda y cumplir con la imposición tributaria. Por falta de una fracción del sector masculino, ellas se veían obligadas a una participación creciente en la vida de la comunidad. El recargo en el trabajo femenino repercutiría también en la fecundidad de las mujeres, reduciéndola ${ }^{26}$. Se añade el hecho que en climas fríos la fase fértil femenina es menor que en climas cáli.dos o tropicales. Ahora bien, considerando que la fase de reproducción de la mujer es limitada, y poniendo como límite superior los 49 años, el 32,7 por 100 de las mujeres en general, y el 36 por 100 de las casadas, ha superado ya

24 Wightman (1983), p. 178. En Sipesipe, «los forasteros fueron menos fértiles que los originarios... En tamaño la familia forastera parece menor...». Sánchez-Albornoz (1983), p. 24.

${ }^{25}$ Salvo las viudas y solteras adultas, las mujeres están empadronadas en la categoría del cónyuge o padre. Queda duda sobre la categorfa original de las esposas, mas, asumiendo que la tendencia general es contraer matrimonio con una persona del mismo status, no pienso existan alteraciones sustanciales.

2* Sánchez-Albornoz (1983 a), p. 42. 
este límite. Livitada resulta ser, entonces, un conjunto envejecido e incapaz de mantener los niveles normales de reproducción.

$\mathrm{La}$ ausencia de familias numerosas no parece haber afectado sustancialmente la estructura demográfica. La corta fertilidad no se debe a un desequilibrio en los factores reproductivos; la razonable proporción entre el número de hombres y mujeres en el grupo comunitario hacen posible una potencial renovación del conjunto. Una amplia mayoría de los adultos tiene una pareja estable unida por matrimonio ( 66 por 100), manteniéndose en ella hasta avanzada edad y renovándola a su desaparición, especialmente entre los hombres: 72 de los 78 viejos tienen esposa al momento del censo.

Además de su participación en la actividad productiva y reproductiva, la mujer cumple su papel social en la estructura familiar. Legalmente no está gravada con las contribuciones estatales, pero se convierte en jefe de familia en caso de enviudar. La edad para contraer matrimonio, como resulta del cuadro 4 , es, en términos generales, a partir de los 18 años para las mujeres y alrededor de los 20 para los hombres. La soltería parece ser condición exclusivamente femenina, ya que no hay varón mayor de 40 años que no sea o haya sido casado. Las viudas son más numerosas que los viudos -35 frente a 11-, quizá debido a que los hombres de edad avanzada tienen mayor posibilidad de contraer nuevamente matrimonio con mujeres más jóvenes.

Por otro lado, las recurrentes epidemias de viruela y sarampión que durante el siglo xviII asolaron el continente no parecen haber ocasionado terribles daños. Estas afectaron sobre todo los centros urbanos que constituyen un caldo de cultivo por la alta densidad. Hay sarampión en Los Andes peruanos en 1618-1619, y reaparece en 1628 y 1634-1635; la viruela ataca en 1632 y no reaparece hasta 1660 en Ecuador. En las décadas siguientes el fenómeno parece atenuarse, aun también porque la población indígena se encontraba ya dentro del circuito epidémico el suficiente tiempo como para que estas formas de infección se vayan transformando de epidémicas en endémicas, proceso que se desenvolvió entre 1500 y 1700 . La desmoralización colectiva y el desgano vital incidieron también sobre el proceso de contracción demográfica ${ }^{27}$.

\section{ESTRUCTURA ESPACIAL}

Situada la comunidad en dos pisos ecológicos bien diferenciados, cada núcleo se divide, a su vez, a la manera andina en ayllus $y$ parcialidades ${ }^{28}$. Un

${ }^{27}$ Dobyns (1963), McNeill (1977) y Sánchez-Albornoz (1977).

2a Ayllu se define como un grupo endógamo que reúne a cierto número de linajes con posesión colectiva de un determinado territorio que los identifica (Wachtel). Esencialmente, cualquier grupo cuyos miembros sean considerados como «del mismo tipo* puede ser 
siglo y medio de presencia española había cambiado la forma y función del tradicional ayllu; sin embargo, éste conservó su papel de ordenador social imponiendo una jerarquía entre sus unidades y sus miembros (por edad, riqueza $\mathrm{u}$ otros criterios locales) ${ }^{29}$. El modelo original estaba ya desintegrado, de modo que no resulta fácil reconstruir la organización prehispánica. No obstante, a partir de la información disponible, trataré de rescatar parcialmente ésta basándome en el esquema a cinco niveles que Platt plantea para las comunidades de Macha, cerca de Potosí ${ }^{30}$. Evidencia de la división quíntuple aplicada al Cuzco por el inca Tupac Yupanqui también se encuentra en la obra del cronista Gutiérrez de Santa Clara ${ }^{31}$.

El esquema propone como unidad social mayor el ayllu madre (ayllu máximo), grupo teóricamente endógamo asentado en un territorio delimitado, pero repartido en más de un piso ecológico. Este se divide en dos mitades: anansaya y urinsaya ${ }^{32}$, tanto en la zona alta como en la baja (respectivamente, la mitad superior y la mitad inferior), gobernadas por un curaca cada una (ayllu mayor). La mitad se divide, a su vez, en cinco unidades que conservan sus nombres tradicionales y son regidos por los jilancus (ayllus menores). Estas se fragmentan en un número variable de unidades llamadas cabildos, y son representadas por un alcalde elegido cada año por rotación entre sus miembros (ayllus mínimos); los anteriores reúnen grupos patrilocales compuestos por unidades domésticas ${ }^{33}$. En el presente censo sólo podré identificar los niveles superiores del esquema debido a las limitaciones de la fuente.

En Livitaca se reconoce una mitad superior anansaya, tanto en la puna como en el valle (véase cuadro 2). Cada anansaya comprende un ayllu Collana, término que significa «la cosa principal», «lo primero», referido a lo más importante o lo más antiguo ${ }^{34}$. Los Collana - dice Zuidema- son uno de los

llamado un ayllu (Spalding). Parcialidad es una de las dos mitades en las que se halla dividido el ayllu en un primer nivel. Para un análisis estructuralista de la división del espacio y de la sociedad inca, revisar el complejo libro de Zuidema (1964). Para un resumen explicativo del mismo, consultar el artículo «Estructuralismo e historia: a propósito de la organización social del Cuzco», en Wachtel (1973), pp. 21-58. También, los artículos de Platt (1978), Harris (1978) y Bouysse-Cassagne (1978).

29 Wightman (1983), pp. 210-211.

${ }^{30}$ Platt (1978).

31 «El [Tupac Yupanqui] también dividió el Cuzco en dos grandes distritos: el primero y más importante lo llamó Hanan-Cuzco, que quiere decir el distrito alto del Cuzco, y el otro Hurin-Cuzco, que significa el distrito bajo. Posteriormente, él dividió el distrito alto en cinco partes, a la primera y más importante la llamó Ayllo Cappa (Capac Ayllu).... Gutiérrez de Santa Clara (1905), p. 435.

${ }_{32}$ Anansaya es una de las mitades en las que está dividido el ayllu; es «la mitad de arriba», al parecer la más importante. Urinsaya, o «la mitad de abajo», corresponde a la otra mitad.

${ }^{33}$ Platt (1978), pp. 1087-1088.

34 Bertonio (1956). 
tres grupos de linaje de que está compuesta la sociedad incaica, son los descendientes directos por vía paterna y materna de un ancestro común importante; se conservan como grupo endógamo y socialmente pertenecen al grupo de los jefes, el de los conquistadores incas ${ }^{35}$.

Por su importancia, los ayllus Collana de Livitaca (puna) y Totora (valle) habrían ido absorbiendo a las cuatro divisiones restantes de su misma parcialidad; en la puna se pueden reconocer - aunque anexadas- dos unidades de la subdivisión: Guruncha y Caiau Quivincha ${ }^{36}$. El padrón registra, en primer lugar, el ayllu Collana de la parcialidad Livitaca anansaya. Allí reside el cacique gobernador - autoridad principal de la comunidad- junto a 85 habitantes. El ayllu principal de la zona baja (Totora) es Culla (¿Collana?) Totora, con 41 residentes, y conserva su propio curaca o cacique.

En la mitad o parcialidad inferior, urinsaya, la división por ayllus se conserva fragmentada. El padrón señala siete ayllus en urinsaya-puna. Los dos sin curaca tienen una composición poblacional distinta, siendo seguramente generados por subdivisiones internas o posteriores. Por un lado está Lliclli Churucava, con amplia mayoría de originarios -14 de sus 18 habitantes-; tal vez se trate de un grupo que se mantuvo al margen de asimilaciones para conservar privilegios, tradición y pureza étnica. Por otro lado está Chagnama, albergando un alto número de forasteros -26 de sus 34 habitantes-, que serviría como grupo de complemento para la producción comunitaria. De entre los restantes cinco ayllus, cada uno con su propio curaca, se reconoce un Caiau - Cayao, que es el tercero de los grupos de la división social que propone Zuidema. Los Cayao son el resto de la población no emparentada con los Collana. Socialmente representan la población vencida, es decir, no inca ${ }^{37}$. Este ayllu Caiau o Cayao, en urinsaya es el único que alberga sólo población originaria (14 hombres y 16 mujeres).

En Totora, la parcialidad de urinsaya-valle tiene un solo cacique para sus cinco ayllus ${ }^{38}$; éste reside en Patagueña, que es el núcleo mayor con 58 ha-

${ }^{3 s}$ Zuidema, en su Sistema de Cegues, propone la distribución del espacio en el Cuzco en un sistema global definido por la repetición. La estructura fundamental del Cuzco resulta esencialmente de la combinación de los dos primeros principios de organización, la tripartición y la cuatripartición, a partir de los grupos de linaje Collana, Payan y Cayao. El segundo sistema de mitades se refiere a las clases (o barrios), la mitad de arriba y la mitad de abajo, es decir, Hanan-Cuzco y Hurin-Cuzco. Y a ello se añade una tercera estructura basada en cuatriparticiones de cada subdivisión. «En resumen - dice Wachtel-: el espacio y la sociedad incas están ordenados de acuerdo a los mismos principios. Estos son: 1. la tripartición; 2 . la cuatripartición (números 2 y 4); 3 . la división decimal (números 5 y 10). Estos principios están combinados según diversas perspectivas, tanto que no dan lugar a una estructura simple, sino a tres complementarias.n Wachtel (1973), p. 35.

${ }^{36}$ Encabezando el recuento se lee: «Pueblo de Livitaca Aillo Collana Guruncha y Caiau Quivincha. Parcialidad de Anansaya». Villanueva Urteaga (1982), p. 320.

37 Zuidema (1964), p. 101.

* Los ayllus son Llusco, Pataguena, Uancaviri, Inga y Alco. En el encabezamiento del 
bitantes, en su mayoría originarios y agregados. La relación de pertenencia del ayllu Uancaviri ( $\sin$ curaca) al ayllu Suntu (urinsaya-puna) sugiere una relación de correspondencia/dependencia del valle frente a su correspondiente en la puna. Así, la unidad ayllu repite la dicotomía puna-valle presente en la estructura global. Pero, entonces, todos los caciques o curacas, tanto los de la mitad inferior y superior como los de arriba (puna) y abajo (valle), tienen el mismo papel, poder y funciones, o dentro de cada comunidad existen grados y papeles diferentes entre ellos.

\section{GRAFICO 1}

Población total

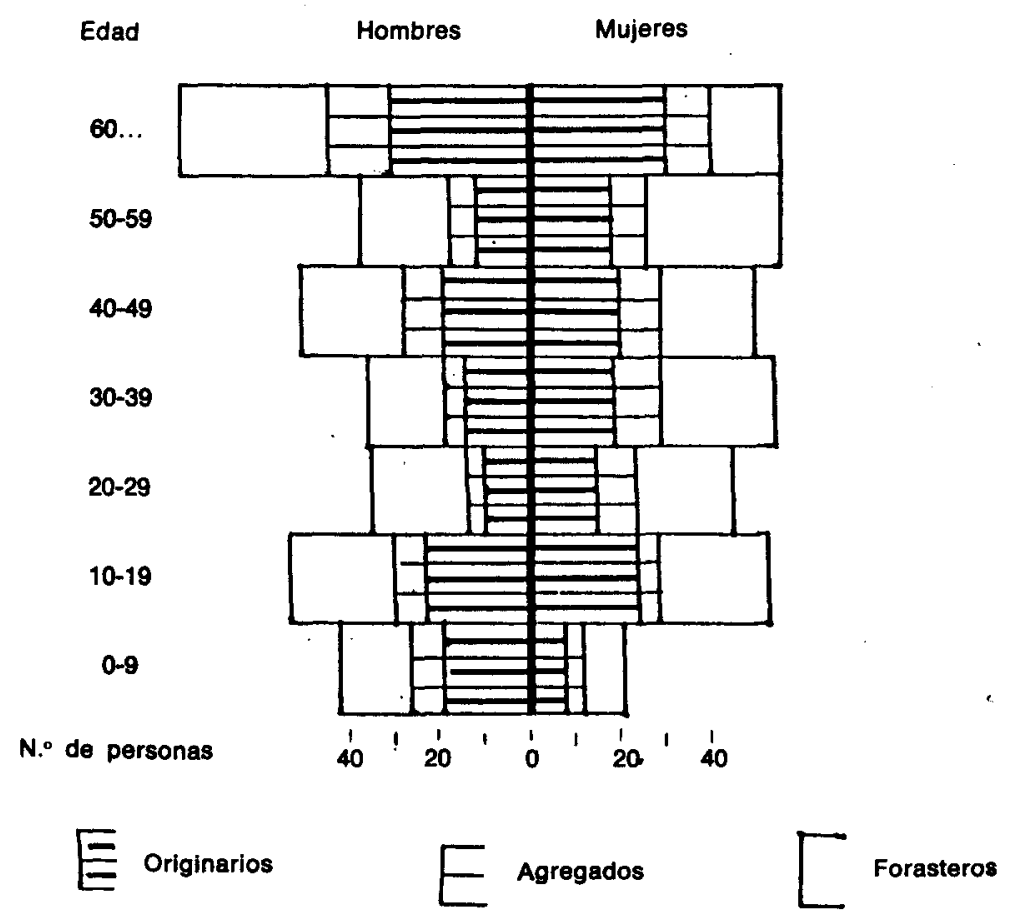

censo del ayllu Pataguena se lee: «Don Diego Roque, casique y segunda persona de los cinco ayllus de 70 as., su muger Maria Choque de 65 as.». Villanueva Urteaga (1982), p. 327. 


\section{FILIACION ETNICA}

Las categorías censales señalan fundamentalmente el status fiscal colonial español de los registrados y, al mismo tiempo, reflejan el orden social interno de la comunidad, organizados en grupos endógamos de parentesco extendido en ayllus, a la manera tradicional. En conjunto, la población está formada por un 39 por 100 de originarios, 16 por 100 de agregados y 45 por 100 de forasteros (véase cuadro 2 ).

El padrón anota cada unidad familiar por separado, señalando el nombre y edades de la mujer y de los hijos. Las viudas y solteras que no viven con sus padres son consideradas jefes de familia por sí mismas, así como los menores de 18 años sin padres. El curaca o cacique; si lo hay, y su familia encabezan la lista de cada ayllu, le siguen las familias de originarios y después las viudas y huérfanos de esta misma condición. Tras ellos están registrados, en el mismo modo, los agregados y los forasteros residentes en cada ayllus. Las fincas de españoles (estancias) sólo tienen población forastera cuyo lugar de origen está señalado en algo más de la mitad de los casos; éstos mantienen contacto con los ayllus de origen, y allí pagan el tributo anual.

\section{Los originarios}

Originarios son los miembros pertenecientes a un núcleo fundador que se reconoce descendiente directo de un ancestro común. Ellos gozan de plenos derechos y obligaciones para el grupo. Están presentes en todos los ayllus, en mayor cantidad en la puna (63 por 100) y en las unidades más nutridas. En el ayllu mayor y de más importancia (Collana), en anansaya-puna, los originarios son el 56 por 100 , y son el 100 por 100 en el mayor y más importante ayllu de urinsaya-puna. En el valle, el ayllu mayor (Culla Totora) alberga un 66 por 100 de éstos y carece de población forastera. El caso opuesto es el ayllu Chagnama (urinsaya-puna), con 34 habitantes; 26 son forasteros, 2 agregados y sólo 3 hombres y 3 mujeres originarios.

Globalmente se aprecia que todos los ayllus tienen, en diferentes proporciones, una mayoría de población originaria. Estos forman un grupo de 261 personas de las 666 del total (128 hombres y 133 mujeres), cuya relación de masculinidad es 96 . Un 24 por 100 tiene menos de 15 años (véase cuadro 3), el 34. por 100 cuenta con más de 50 años y su población activa alcan$\mathrm{za}$ al 42 por 100 (véase gráfico 1 ). La desproporción entre hombres y mujeres en la poblatión activa originaria ( 43 hombres por 64 mujeres) sugiere una huida o emigración masculina adulta a mediano plazo, hasta cumplir los 51 años 
y estar exceptuados del pago del tributo. En las cifras globales la presencia de niños compensa la alteración.

Lamentablemente, los ausentes no están anotados en el padrón general. La dispersión de originarios fue común en las comunidades de la zona andina, y tuvo lugar también en Livitaca. A falta de información directa documental o de fuentes alternativas no podemos estar seguros de su magnitud. Los «huidos» o fugitivos formaron un grupo abigarrado de forasteros en todas sus variantes: agregados, forasteros, yanaconas, etc., necesitados de un lugar donde asentarse. Livitaca fue receptora de inmigrantes; un 60 por 100 de sus residentes era de tal procedencia, siendo absorbidos como agregados o forasteros.

\section{Los agregados}

Agregados son los residentes forasteros ya integrados en la comunidad. Pagan la mitad del tributo ${ }^{39}$, mas no gozan de los mismos derechos y prerrogativas que los originarios al momento de repartir las tierras comunales, en la partición de la riqueza colectiva y en el ejercicio del poder dentro del grupo, según un arreglo concordado internamente entre los habitantes de los ayllus. La tributación por origen data de antiguo; la organización toledana (1575) la confirma y sólo en tiempos del duque de La Palata, a fines del siglo xvir, se pensará en la tasación territorial del tributo ${ }^{*}$. La medida no prosperó pese a que la magnitud de la migración intercomunitaria e interregional eran tan evidentes que no podían ignorarse. El ayllu tuvo que hacerse cargo de reubicar a los migrantes nativos. Su absorción dentro del propio grupo de identificación supuso una serie de adaptaciones en la estructura tradicional, flexibilizando las severas reglas de aceptación social y de matrimonio, y alterando el modelo de distribución de tierras colectivas y cambiando las tareas de cada comunero. Los agregados quedan en una condición ambigua: se los podría considerar como forasteros privilegiados desde el momento que seguramente gozan de algún tipo de beneficio inmediato, aunque no tienen acceso al grupo de poder. Pueden ser también la segunda o tercera generación de antiguos inmigrantes, nacidos en el lugar y, por ello, con una mayor capacidad y posibilidad de integración.

De los 106 individuos agregados, un 68 por 100 se asienta en el valle, donde hay tantos como originarios; en cambio, en la parte alta (puna) son pocos los asimilados ( 33 de 297 habitantes). Este sector abarca el 16 por 100 del total, y el 50 por 100 están entre los 15 y 50 años. Los niños menores

39 Se lee en el padrón: «indios forasteros agregados a este aillo que pagan la mitad de los tributosw. Villanueva Urteaga (1982), p. 321.

*ole (1984), p. 45. 
de 15 años son el 19 por 100 y los que tienen más de 50 años alcanzan al 35 por 100 (véase cuadro 3).

De los catorce ayllus, cuatro no albergan agregados. Proporcionalmente, la mayor concentración está en el ayllu Inga de urinsaya-valle, donde resultan ser cuatro veces más que los originarios. Cabría pensar en una compensación numérica y tributaria de los fugitivos, además de creer que la asimilación resulta más fácil en el caso que los recién llegados fueran descendientes de mitimaes, colonos mitmao o comuneros separados de su ayllu por la reorganización colonial ${ }^{41}$.

La categoría encierra una mayor cantidad de mujeres que de varones, y un número más alto dé hombres viejos respecto de las mujeres de la misma edad. La población activa femenina es capaz de aportar trabajo productivo y generar riqueza supliendo la falta de tributarios. Resta por descubrir si esta respuesta fue una reacción individual o una política de la comunidad pensando en la supervivencia a largo plazo.

Las edades son tendencialmente altas; por ejemplo, en Culla Totora, 4 hombres y 4 mujeres de 14 habitantes tienen más de 50 años, y, pese a que un tercio de las mujeres están en edad fértil, el número de niños es comparativamente muy bajo: el 20 por 100 de la población agregada.

\section{Los forasteros}

Forasteros son aquellos miembros de otras comunidades residentes en el área censada que pagan tributos en sus comunidades de origen. No son siempre habitantes de reciente arribada; un largo tiempo de residencia no garantiza su proceso de asimilación paulatina. La condición de forastero es hereditaria, y parece no haber distinción entre veteranos y recién llegados. El grupo de identificación y la posición social son entonces átributos condicionados por los padres de acuerdo con la estructura de casta de la sociedad indígena ${ }^{42}$.

El empadronamiento de $1645^{\circ}$ indica que los indios forasteros eran el 37 por 100 , y la posterior numeración de La Patala arroja un 40 por $100^{43}$. Al norte y al oeste de Collao llegan a ser la mitad, y también hay una alta concentración en la zona Cuzco-Puno, lo que quiere decir, según Wightman, que los trabajadores mitayos en su traslado hacia las minas habian decidido acomodarse en el valle del río Vilcanota ${ }^{44}$.

Un 45 por 100 de la población total está formada por forasteros; son

\footnotetext{
"Wightman (1983), p. 182.

"2 Wightman (1983), pp. 32-33, y Sánchez-Albornoz (1983 a), p. 37.

${ }^{4}$ Sánchez-Albornoz (1983 a), p. 37.

4 Wightman (1983), pp. 41-42.
} 
el 25 por 100 del total de habitantes de la puna, el 20 por 100 de los del valle y el 100 por 100 de los de las estancias. Un tercio vive en nueve de los catorce ayllus. En Collana, el centro principal de anansaya-puna son la cuarta parte; en Chagnama, las tres cuartas partes, y la mitad en Uancaviri, ambas unidades en urinsaya-valle. En el resto la presencia forastera es moderada (véase cuadro 3 ).

Incluyendo a la población de las estancias, el peso numérico de este sector en el conjunto se incrementa notablemente. Hay en ellas 189 personas, 100 hombres y 89 mujeres. La mayoría masculina sugiere que la estancia fue refugio para evasores de tributos. La estancia Calani es más grande, con 48 pobladores, y, de éstos, 37 están entre los 15 y 50 años, junto a 9 viejos y 2 adolescentes; no hay registro de menores de 10 años. La estancia más pequeña es Chila, con 16 habitantes, 10 mujeres frente a 6 hombres, y no se señala población infantil.

\section{PROCEDENCIA DE LOS INMIGRANTES}

El documento en análisis muestra que la población forastera llega desde zonas aledañas de montaña y desde comunidades que seguramente funcionaban bajo los mismos patrones y principios. Pese a que algunos funcionarios de la Corona aseguraban que los indios habían huido a regiones fuera del control español, no se desconocía el fenómeno de la movilidad intercomunitaria en áreas más bien limitadas ${ }^{45}$.

El lugar de origen de estos forasteros está señalado en el padrón general por unidad familiar, es decir, indicando la procedencia de la cabeza en el caso de una familia nuclear, o de la viuda o el soltero en otros casos. La filiación al ayllu de origen era útil para la recolección del tributo, y por esto el cacique, en su doble papel de autoridad india y de funcionario estatal, tiene especial interés en que conste. El lugar de procedencia de las mujeres no interesa al Estado, y por ello no suele registrarse.

Pese a la tendencia general del ayllu a la endogamia, el modo más simple para entrar en la comunidad es contraer matrimonio con un originario, previa aprobación pública del grupo. Como consorte de un comunero - sobrino en el léxico local-, se garantizaría al forastero el acceso a tierras comunales en desuso o abandonadas. Se le pide, en cambio, el pago de ciertas obligaciones tributarias ${ }^{* 6}$.

45 Ya señalado por el virrey don Francisco de Borja, príncipe de Esquilache (1614. 1620), en su relación. Véase Hanke (1978).

w Wightman (1983), p. 182. 
El control que los ayllus tienen sobre la unión conyugal entre sus miembros es significativo para la supervivencia del orden social basado en cánones endogámicos. Si bien el matrimonio no queda consolidado hasta ser certificado por una autoridad religiosa colonial, la elección de la pareja queda como un proceso interno llevado a cabo de acuerdo con las costumbres locales. Esta regulación sobre el matrimonio es la principal defensa contra las presiones externas que amenazaban con transformar el ayllu de un grupo de parentesco en una corporación de intereses colectivos ${ }^{47}$.

El censo señala el lugar de origen de 58 jefes de familia forasteros de los 107 asentados en los tres núcleos: 30 en Livitaca (28 por 100), 15 en Totora (14 por 100) y 62 en las estancias (58 por 100). Las procedencias son 27 diferentes esparcidas en seis corregimientos. El 37 por 100, o 22 personas, llegan de ocho pueblos del corregimiento de Collaguas. Hay menos representantes de los lugares más alejados, aunque la distancia no está necesariamente en relación con el número de inmigrantes (véase cuadro 6 y mapa). No hay ningún pueblo o área que pueda ser considerada como abastecedora principal de material humano, llegan de una a cinco personos de cada uno de los pueblos anotados.

Los migrantes provienen de zonas no muy alejadas del lugar de asentamiento. El pueblo más alejado es Chucuito, a orillas del lago Titicaca (véase mapa), y sigue en Lampa, que es también una población altiplánica. Otros dos puntos de cesión de forasteros son la zona de Ayaviri, hoy en el Departamento de Puno, correspondiente al corregimiento de Urcosuyo en la Administración española, y la zona de Caylloma - centro minero importante- en el corregimiento de Collaguas (hoy Arequipa). Ambos están situados a uno y otro lado de la cadena montañosa de Los Andes.

Si trazamos un círculo imaginario en torno al pueblo de Livitaca con un radio de $55 \mathrm{Km}$., aproximadamente (distancia que hay en línea recta entre Livitaca y Sicuani), quedan dentro de él 14 de los 27 pueblos señalados, todos ellos en el actual Departamento del Cuzco. Más allá, dentro de un segundo círculo, se encuentran el pueblo de Caylloma y, también, los de Sivayo, Chiguayo, Tisco y Topay, del actual Departamento de Arequipa; en el Departamento de Puno están los pueblos de Orurillo, Ayaviri, y por el Norte la ciudad del Cuzco. Fuera del segundo anillo están los pueblos de Lampa y Chucuito, ambos en el altiplano. Hay dos casos excepcionales, un platero venido desde la ciudad del Cuzco y asentado en el ayllu Chagnama y una familia llegada desde el «pueblo de La Paz», probablemente la actual ciudad de La Paz, en Bolivia, cuyo nombre original es Chuquiabo.

La tendencia general de esta corriente migratoria es la de seguir la línea

47 Wightman (1983), p. 178. 


\section{CUADRO 6}

Procedencia y destino de los inmigrantes

\begin{tabular}{|c|c|c|c|c|c|c|}
\hline \multicolumn{2}{|c|}{ PROCEDENCIA } & \multicolumn{3}{|c|}{ DESTINO } & \multirow[b]{2}{*}{ Total } & \multirow[b]{2}{*}{$\begin{array}{l}\text { Propor- } \\
\text { ción (\%) }\end{array}$} \\
\hline Corregimiento & Pueblo & $\begin{array}{l}\text { Livi- } \\
\text { taca }\end{array}$ & Totora & $\begin{array}{c}\text { Estan- } \\
\text { cias }\end{array}$ & & \\
\hline Chumbivilcas & $\begin{array}{l}\text { Chamaca ... } \\
\text { Checca .... } \\
\text { Colquemarca . } \\
\text { Llusco . . . } \\
\text { Santo Tomás. } \\
\text { Usco . . . . } \\
\text { Velille . . . . }\end{array}$ & $\begin{array}{l}4 \\
1 \\
\frac{1}{-} \\
1\end{array}$ & $\begin{array}{l}- \\
\frac{1}{-} \\
-\end{array}$ & $\begin{array}{r}-4 \\
-1 \\
1 \\
1 \\
-\end{array}$ & & \\
\hline Chilques (1) & $\begin{array}{l}\text { Accha . . } \\
\text { Checcasupa . } \\
\text { Omacha . . }\end{array}$ & $\begin{array}{r}5 \\
1 \\
-\end{array}$ & - & $\frac{2}{1}$ & 15 & 14 \\
\hline Canas y Canches (2) & $\begin{array}{l}\text { Coporaque ... } \\
\text { Maras . . . } \\
\text { Pichigua . . } \\
\text { Yauri . . } \\
\text { Sicuani . . . }\end{array}$ & $\frac{1}{\frac{1}{2}}$ & $\begin{array}{l}\overline{1} \\
\overline{-}\end{array}$ & $\begin{array}{l}2 \\
3 \\
1 \\
2 \\
1\end{array}$ & 9 & 8 \\
\hline Collaguas (3) & $\begin{array}{l}\text { Cailloma .... } \\
\text { Chiguayo ... } \\
\text { Sibayo* . . } \\
\text { Tisco . . . } \\
\text { Topay . . . }\end{array}$ & $\begin{array}{l}3 \\
1 \\
- \\
1\end{array}$ & $\begin{array}{l}\overline{2} \\
1 \\
1 \\
-\end{array}$ & $\begin{array}{l}1 \\
- \\
-\end{array}$ & 13 & 12 \\
\hline Urcosuyo (4) & $\begin{array}{l}\text { Ayaviri . . . . } \\
\text { Lampa . . } \\
\text { Orurillo . . }\end{array}$ & E & - & $\begin{array}{l}2 \\
2 \\
1\end{array}$ & 10 & 9 \\
\hline Chucuito (4) & $\begin{array}{l}\text { Chucuito ... } \\
\text { Quinota . . }\end{array}$ & $\overline{2}$ & - & $\underline{2}$ & 5 & 5 \\
\hline Sin especificar $\ldots \ldots$ & 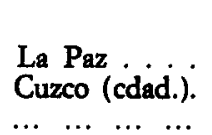 & $\begin{array}{l}1 \\
1 \\
5\end{array}$ & $\frac{-}{9}$ & $\overline{-}$ & $\begin{array}{r}4 \\
1 \\
1 \\
49\end{array}$ & $\begin{array}{r}4 \\
1 \\
1 \\
46\end{array}$ \\
\hline TotaL $\ldots \ldots \ldots$ & $\ldots \ldots \ldots, \ldots$ & & & & 107 & 100 \\
\hline
\end{tabular}

(1) Hoy provincia de Paruro, Departamento del Cuzco.

(2) Hoy provincia de Espinar, Departamento del Cuzco.

(3) Hoy Departamento de Arequipa.

(4) Hoy Departamento de Puno.

* También Sivaio. 


\section{MAPA 1}

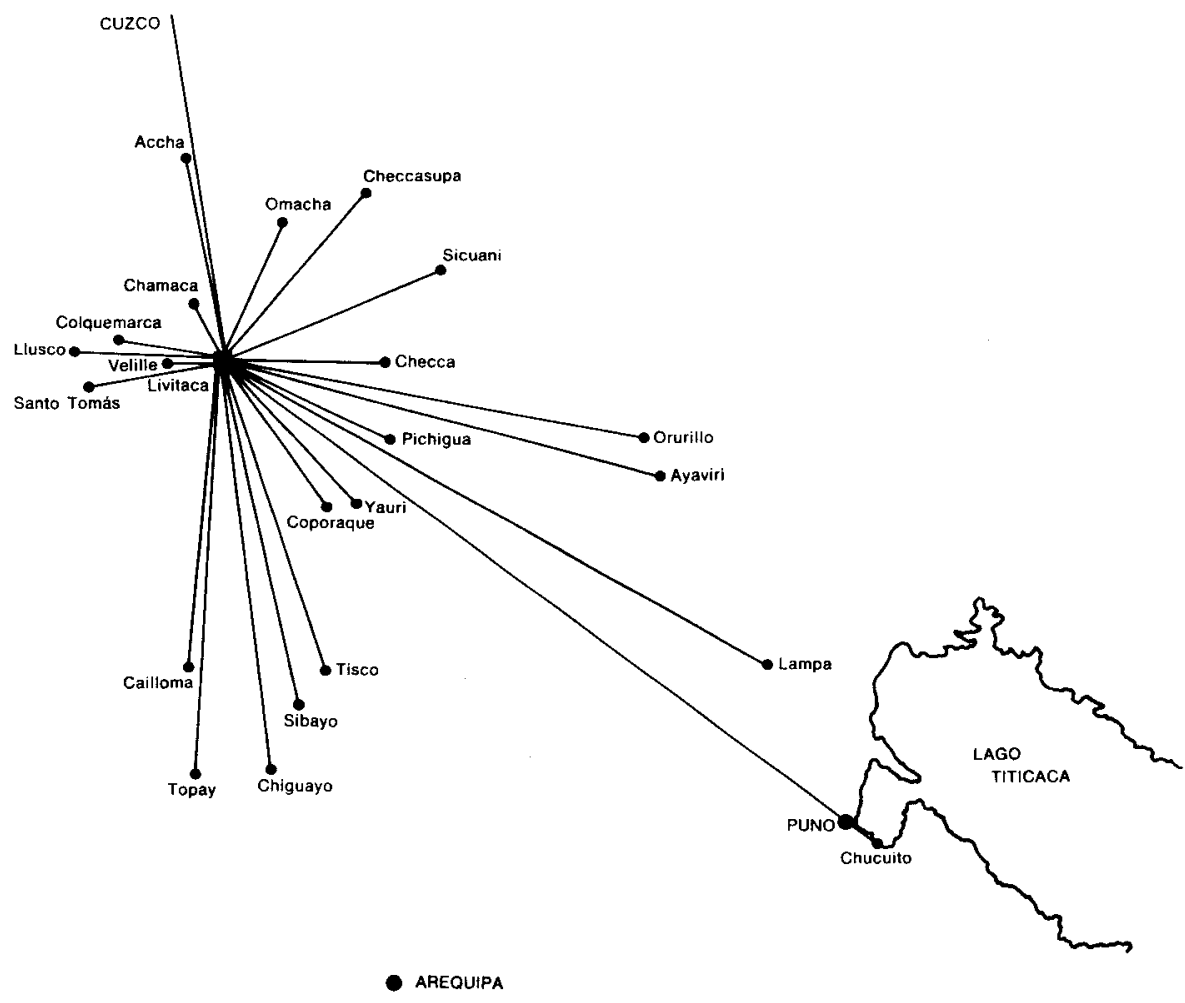

de zonas frías de alta montaña ${ }^{48}$. La distancia que los separa del lugar de origen es relativamente corta. El territorio está a una altura de 3.500 a $4.000 \mathrm{~m}$. s. n. m., en un medio ambiente muy similar al de proveniencia, al contrario de lo que ocurre con casos como el de Sipesipe (Cochabamba), donde buena parte de los forasteros, después de recorrer grandes distancias, llegan desde zonas altiplánicas o de montaña a instalarse en una zona templada de valles sin haber tenido contacto previo con la región ${ }^{49}$. En ambos casos hay, sin embargo, una alta dispersión de los lugares de procedencia, lo que refleja la ausencia de movimientos de masa organizados. Se prefiere el traslado del grupo familiar nuclear en modo independiente.

* Para conocer las alturas de los pueblos, consultar el Catálogo (1979).

49 Sánchez-Albornoz (1983), p. 34. 
La comunidad agrícola de Livitaca, situada fuera de las rutas comerciales y de intercambio, ha visto alterada su tradicional estructura socioeconómica por las normas y deberes que el Gobierno colonial español introdujo. Los ayllus cambiaron su orden y fisonomía, se dividieron o unieron aceptando convivir con las haciendas a las que tuvieron que ceder tierras y hombres. Internamente, el ayllu rompió su rígido sistema social, basado en lazos de parentesco, para mantener el nivel de producción, necesario a la supervivencia, y contrarrestar la pérdida de su potencial humano. Hay, por un lado, un envejecimiento del conjunto que no permite una reproducción a niveles normales, $y$, por el otro, un doble flujo migratorio que expulsa, pero también atrae recursos humanos que renuevan y, quizá, vitalizan la comunidad. Al mismo tiempo, ésta se ve obligada a sostener una gran cantidad de ancianos -especialmente varones - cuya capacidad productiva es sin duda limitada.

Disminuida la vitalidad global, el proceso de renovación se hace cada vez más lento y menos eficaz, agudizado por el reducido número de hijos que las parejas jóvenes tienen, frente a los dos o más por familia, que arrojan cálculos para fechas más tempranas ${ }^{50}$. Hay, por lo tanto, una baja tasa de fertilidad reforzada por la avanzada edad de las mujeres. El corto número de niños parece ser una distorsión del empadronamiento debido al subregistro de niñas, ya que de continuar estrechándose la base poblacional se presentaría una muy severa depresión.

En cuanto a la composición social de la población, el análisis del padrón hace ver que la comunidad está básicamente dividida por mitades entre originarios y forasteros. El flujo migratorio ocasiona una importante disminución del sector activo masculino originario, especialmente aquel en edad de tributar; también hay disminución en el sector femenino, pero en menor proporción. El fenómeno tiene como causa, no única, la evasión de las obligaciones impositivas estatales.

Livitaca recibe en compensación inmigrantes de otras comunidades rurales - sólo en casos excepcionales de centros urbanos-y los acomoda ya sea en el seno de sus ayllus o en las estancias de españoles. Estos forasteros reemplazan la falta de brazos y logran mantener la productividad de la zona a niveles de supervivencia salvando a la región de la depresión. La migración individual o familiar, y no en grandes grupos, trae forasteros con pocos recursos que encuentran también pocas oportunidades.

Pese a este retemplazo de la fuerza de trabajo, la estructura de la institución socioeconómica andina se resiente y se ve obligada a integrar parcialmente, con fines netamente utilitarios, a elementos ajenos, que son los que forman el grupo de los agregados. La sustitución de originarios por forasteros no pa-

so Sánchez-Albornoz (1983), p. 22, y Renique y Trelles (1977), p. 182. 
rece haber desintegrado los canales de selección del conjunto étnico, sino que modificó paulatinamente el grupo de identificación con el concurso de causas de diversa naturaleza: económicas, sociales, políticas y culturales.

\section{BIBLIOGRAFIA}

ATLAS H ISTÓRIco (1970): Atlas bistórico y geográfico de paisajes peruanos (elaborado durante los años 1963-70), Lima, Instituto Nacional de Planificación, Asesoría Geográfica.

Bertonio, Ludovico (1956): Vocabulario de la lengua aymará (impreso en la Casa de la Compañía de Jesús de Juli, pueblo de la provincia de Chucuito, por Francisco del Canto, 1612), La Paz, Don Bosco.

BouYSEE-CASSAGNE, Therèse (1978): "L'espace aymara: urco et uma», Annales, 33.

CATÁlogo (1979): Catálogo de nombres geográficos del Perú, Parte I, Lima, Instituto Geográfico Militar, Ministerio de Guerra.

Cole, Jeffrey (1984): \&Viceregal Persistance Versus Indian Mobility. The Impact of the Duque de La Palata's Reform on Alto Peru, 1681-1692», Latin American Research Review, 1, pp. 37.56.

Colin, Michele (1966): Le Cuzco d la fin $d u X V I I^{e}$ et au debut du XVIII siècle, París, Institut des Hautes Etudes de l'Amerique Latine.

Cook, Noble David (ed.) (1975): Tasa de la Visita General de Francisco de Toledo, Lima, Universidad Nacional de San Marcos.

- (1981): Demographic Collapse. Indian Peru, 1520-1620, Cambridge, Cambridge University Press.

- (1982): «Population Data for Indian Peru: Sixteenth and Seventeenth Centuries», Hispanic American Historial Review, 62/1, pp. 73-120.

Dollrus, Olivier (1981): El reto del espacio peruano, Lima, Instituto de Estudios Peruanos.

Dobyns, Henry F. (1963): «An outline of Andean Epidemic History to 1720», Bulletin of the History of Medicine, 37, pp. 493-515.

Gutiérrez de Santa Clara, Pedro (1905): Historia de las guerras civiles del Perú (1544-1548), tomo tercero, Col. Libr. Doc. Ref. Hist. América, Madrid.

Hanke, Lewis (ed.) (1978): «Relación del Príncipe de Esquilache», sin fecha (¿1621?), en Los virreyes españoles en América durante el gobierno de la Casa de Austria. Perú, 7 vols., Biblioteca de Autores Españoles, tomos 280-286, Madrid, Ediciones Atlas, vol. II, pp. 167-182.

Harris, Olivia (1978): «De l'asymetrie au triangle. Transformation symboliques au Nord de Potosiw, Annales, 33, pp. 1108-1125.

JIMÉNEZ DE LA ESPADA, Marcos (1965): «Relación fecha por el corregidor de los Chumbivilcas don Francisco de Ocaña, por mandado de V. Exa. el Sr. Dn. Fernando de Torres y Portugal visorrey destos Reynos para la descripción de los indios que S. M. manda hacerw, en Relaciones geográficas de Indias - Perú, Biblioteca de Autores Españoles, vol. 183, Madrid, Ediciones Atlas, pp. 310-332.

LOPEZ BELTRAN, Clara (1985): «La justicia en el Imperio Incaico», Historia y Cultura, 8 , pp. $1-32$.

McNkInL, William H. (1977): Plagues and People, Garden City (N. Y.), Anchor Books.

Morner, Magnus (1978): Perfil de la sociedad rural del Cuzco a fines de la colonia, Lima, Universidad del Pacifico. 
MuRRa, John V. (1975): Formaciones económicas y politica en el mundo andino, Lima, Instituto de Estudios Peruanos.

Platt, Tristan (1978): «Symetries en miroir», Annales, 33, pp. 1081-1107.

Renique, José Luis, y Trelles A., Efraín (1977): «Aproximación demográfica, YaqueCollaguas, 1591», en Collaguas, I, Lima, Pontificia Universidad Católica del Perú, Fondo Editorial, pp. 169-190.

SAIgnes, Thierry (1978): «De la filiation a la residance: les ethnies dans les vallées de Larecaja», Annales, 33, pp. 1160-1181.

- (1979): "Valles y punas en el debate colonial. La pugna sobre los pobladores de Larecaja», Revista Histórica, 3, pp. 141-164.

- (1981): «Les lupacas dans les vallées orientales des Andes. Trajects spatiaux et repreres demographiques (xvi'-XvIIr siècles)», Melanges de la Casa de Velázquez, 17, pp. 147-182.

Sánch ez-Albornoz, Nicolás (1977): La población de América Latina desde tiempos precolombinos al año 2000, Madrid, Alianza Editorial.

- (1982): «Migraciones internas en el Alto Perú. El saldo acumulado en 1645», Historia Boliviana, 2/1, pp. 11-19.

- (1982 a): «Migración urbana y trabajo. Los indios de Arequipa, 1571-1645», en De bis. toria e bistoriadores. Homenaje a José Luis Romero, México, pp. 259-281.

- (1983): «Migración rural de los Andes. Sipesipe (Cochabamba), 1645», Revista DE Historia ECONÓmica, I, pp. 13-36.

- (1983 a): «Mita, migraciones y pueblos. Variaciones en el espacio y en el tiempo. Alto Perú, 1573-1692", Historia Boliviana, 3/1, pp. 31-59.

Spalding, Karen (1974): De indio a campesino. Cambios en la estructura social del Perú colonial, Lima, Instituto de Estudios Peruanos.

Villanueva Urteaga, Horacio (pról. y trans.) (1982): Cuzco 1689. Informes de los párrocos al obispo Mollinedo. Economía y sociedad en el sur andino (Prefacio de $\mathrm{Pa}$ blo Macera), Cuzco, Centro de Estudios Rurales Andinos «Bartolomé de Las Casas».

VollmeR, Günter (1967): Bevolkerungspolitik und Bevolkerungsstruktur im Vizekonigreich Peru su Ende der Kolonialzeit (1741-1821), Bad Hamburg vor der Hole.

WaCh TEL, Nathan (1973): Sociedad e ideologia. Ensayos de bistoria y antropologia andinas, Lima, Instituto de Estudios Peruanos.

Wig h tMan, Ann Margaret (1983): From Caste to Class in the Andean "Sierra»: The Seventeentb Century "Forasteros» of Cuzco (inédito), Ph. D. Thesis, Yale University.

Zuidema, R. T. (1964): The Ceque System of Cuzco. The Social Organization of the Capital of the Inca, Leiden, E. J. Brill. 